\title{
The Last Lecture
}

by Randy Pausch and Jeffrey Zaslow

Published by Hyperion, 2008, 206 pages

Reviewed by:

Steven L. Estes (sestes@niu.edu), Academic Advisor, College of Liberal Arts \& Sciences, Northern Illinois University

Within days of delivering his 2007 lecture, Really Achieving Your Childhood Dreams, Dr. Randy Pausch, a computer science professor at Carnegie Mellon University, inspired millions with his positive outlook in the face of his diagnosis of terminal pancreatic cancer. Pausch's book, The Last Lecture, consists of a series of 61 reflective anecdotes dictated to co-author Jeffrey Zaslow, many with titles which serve as motivational mantras.

\section{Overview}

In Chapter 1, "An Injured Lion Still Wants to Roar," Pausch contemplates his motivation for presenting his lecture despite the wishes of his spouse to spend as much time with their family as possible. As the chapter title implies, he decides that his "natural habitat" is in the classroom teaching. In addition to students, though, the audience he hoped would embrace his message would be his three children when they are older.

Inspired by advice from his father, Pausch, in Chapter 3, "The Elephant in The Room," describes how he paved the way for his positive message by helping the audience accept and feel comfortable with his condition. In "The Park is Open Until 8 p.m." (Chapter 12), he observed that his doctor's approach to expressing how long Pausch had to live reminded him of the customer service lessons that Pausch learned while working for Disney. His appreciation for such personal skills is evident throughout the book, but his techniques are specifically outlined in "Start by Sitting Together" (Chapter 35), where he introduces his seven-step method for working with others.

Pausch expresses gratitude toward others who helped him achieve his dreams in equal measure with those who encouraged him to dream in the first place. When an eight-year-old Pausch attended summer camp in 1969, the camp counselors determined that bedtime was more important than watching television coverage of Neil Armstrong's first steps on the moon. But his father took a picture of the moment on television, knowing the impact it could have on his son. His dreams were visually manifested as a teenager when his parents allowed him to paint whatever he wanted on his bedroom walls and ceiling. A humorous illustration of Snow White's mirror expressed his dream to work for Disney. A painting of a rocket symbolized his dreams of experiencing zero gravity and becoming the Star Trek character, Captain Kirk.

Clues to how he managed to realize these dreams are found in what some of his students refer to as "Pauschisms" such as, "You can always change your plan, but only if you have one" (p. 108). After explaining the plan he had to get to zero gravity by offering some extra publicity for NASA, he suggests: "Have something to bring to the table, because that will make you more welcome" (p. 33). The most profound "Pauschism" is born out of his discovery 
that bringing his Ph.D. to the table is not a magic ticket to employment in the "magic kingdom" when he notes, "The brick walls are there for a reason. They're not there to keep us out. The brick walls are there to give us a chance to show how badly we want something" (p. 51-52).

Pausch's dream to play in the NFL was one brick wall he was unable to overcome. Still, he reports that he may have learned more from pursuing that dream than any other, thanks to a rather stern coach. He recalls one practice when Coach Graham gave Pausch a particularly tough time. The assistant coach explained that this was a positive sign because if you're making mistakes, "and nobody says anything to you anymore, that means they've given up on you." Pausch knew that not only had his coach not given up on him, but that he was trying to help him develop self-esteem the way Coach Graham knew it had to be done: "You give them something they can't do, they work hard until they find they can do it, and you just keep repeating the process" (p. 37). Though that process never got him as far as the NFL, he recognized it as a type of "head-fake learning" (p. 39). In football, a head-fake literally refers to a head movement used to mislead an opponent in the wrong direction. According to Pausch, head-fake learning “teaches people things they don't realize they're learning until well into the process" (p. 39).

Anyone who has seen the Star Wars series knows that "Training a Jedi" (Chapter 25) involves quite a bit of this kind of learning as well as a healthy dose of reality from Master Yoda. Pausch knew how to provide students with both "head-fakes" and reality checks, thanks to his childhood football mentor. When a student named Tommy Burnett expressed his dream of working on the next set of Star Wars films in 1993, Pausch had his doubts since there had been no announcement of a second trilogy. However, he knew from experience that there was value in pursuing even the wildest dreams. Burnett joined Pausch's research team and was exposed to the kind of blunt feedback that Pausch had experienced when playing for Coach Graham. Acquiring the skills which Industrial Light \& Magic was looking for when they began preparation for a second Star Wars trilogy, Burnett had the opportunity to work on each film. Pausch discovered what those of us who have worked in higher education already know that "enabling the dreams of others is even more fun" (p. 117).

\section{Application}

Evolving from Appreciative Inquiry (Cooperrider, Sorenson, Whitney, \& Yaeger, 2000), Appreciative Advising (Bloom, Hutson, \& He, 2008) proposes enabling students' dreams through a six-phase process: Disarm, Discover, Dream, Design, Deliver, and Don't Settle. The first "head-fake" here is that these principles apply not only to academic advisors, but to anyone who instructs or leads college students. The second "head-fake" is that in The Last Lecture, Pausch provides the ideal textbook to engage our first-year students in the Appreciative Advising process-a process which should extend beyond advising offices to classrooms and orientation programs. As a selection for a common reading experience, The Last Lecture could facilitate extending this process to other units while inspiring students to pursue their dreams.

The Last Lecture can "Disarm" students as it reveals that professors are people who struggle with health, work, and relationships just like students. With academia as the backdrop for many chapters, The Last Lecture allows students to observe college from the perspective of a professor. In doing so, Pausch helps break the ice between students and professors. Orientation programs lead the way when it comes to establishing a sense of comfort with their 
new surroundings, but advisors and instructors must also be mindful of the "elephants" in the room. At this early stage, the "elephants" often take the form of anxiety. Whether it is anxiety about connecting with their roommate, the loss of connection with their family and friends at home, or connecting the dots on the campus map, the solution begins with helpful faculty and staff making a connection with the student.

"Discovery" encourages students to explore and feel more connected to their own unique experiences and strengths. The Last Lecture models discovery through Pausch's introspective journeys into his role models, experiences, and triumphs. Zaslow (2008) even offers a helpful series of discussion questions online in The Last Lecture Educator's Guide. For example, when discussing Chapter 11, "The Happiest Place on Earth," Zaslow (2008) suggests asking "What are the brick walls you've faced in your own life? How did you get over them?" (p. 2) Such questions could begin a classroom discussion or prompt a short writing assignment in a first-year experience course. Furthermore, they meet the criteria of "questions that will elicit stories from students" (p. 44), described by Bloom et al. (2008) as a key feature of the "Discovery" phase.

Some of Zaslow's discussion questions are as helpful for the "Discovery" phase as they are the "Dream" phase. For example, one of the questions pertaining to Pausch's unfortunate 1969 summer camp experience asks students to recall "Have you ever wished adults in your life were less rigid?" (p. 3). Such questioning helps students analyze personal barriers to visualizing their dreams. Bloom et al. (2008) suggest that "creating powerful images" is the key to the "Dream" phase. This suggestion could be carried out by assigning students the task of freely drawing their dreams in the spirit of Pausch's bedroom wall project. However they are visualized, The Last Lecture encourages the reader to find value in all dreams, whether they are as humble as winning a stuffed animal or as ambitious as experiencing zero-gravity.

No matter the magnitude of the dream, pursing it requires careful "Design." This may seem like the point where advising parts ways with orientation programs and first-year experience courses. However, the "Design" phase shares much in common with the objectives of such programs as it seeks to encourage the student to develop resources such as decision-making skills and a network of supportive people. using questions such as "What does the student want to see on his/her ideal résumé?" (p. 75). Assigning a hypothetical résumé as part of my first-year experience course has helped students recognize the need for immediate and long-term goals. Part of the task involves having students consider whom they would cite as references. They may not know specific names at this stage, but as they consider independent studies or internships as examples on their résumé, they begin to see where such references could originate. The Last Lecture makes this idea more salient by giving examples of Pausch's own mentoring experiences on his journey over the brick walls.

What should our network of supportive orientation leaders, advisors, and instructors "Deliver?" According to Pausch, higher education should deliver an experience akin to a "personal trainer in an athletic club (p. 113)." Like a personal trainer, an Appreciative Advisor can be someone who can "energize the student with confidence" and "reminds the student not to panic in the face of obstacles" (Bloom et al., 2008, p. 96). However, students may not realize they are facing an obstacle if they do not learn to assess themselves.

From Burnett's success to Pausch's quest to squeeze as much as he could out of his limited time, The Last Lecture urges that we "Don't Settle." Pausch believes that teachers should settle for nothing less than "to help students learn how to judge themselves" (p. 112). To that 
end, Bloom et al. (2008) suggest a "personal success letter" (p. 102) as a capstone for a first-year experience course to encourage growth through self-monitoring. With The Last Lecture as a text, such an exercise might involve a reflective writing project with their "last lecture" as the theme. What wisdom have they acquired during their transition into college? What advice would they share with next year's first-year students?

After using The Last Lecture in our common reading program at Northern Illinois University, many students were inspired to volunteer as peer instructors, citing enthusiasm for the book. (NIU peer instructors are continuing students who assist first-year students in university experience courses.) The Last Lecture was considered either a "somewhat good choice" or a "very good choice" by 73\% (275 responses) of those enrolled in common reading experience sections.

Although the lack of chronological organization of the book might be perceived as a drawback to some students, it affords instructors the opportunity to weave the material with topics from their first-year experience course syllabi with relative ease. The widely available video of Pausch's lecture inevitably raises questions about using the video in class. Since the book covers much more of the story behind the lecture, the two materials complement each other nicely. However, instructors should consider whether showing a video early in the term sets the tone of the course as a passive classroom experience versus active with vibrant discussions.

As a common reading experience selection, The Last Lecture offers opportunities for lively discussions, motivation, and material for developing broad perspectives. It reflects Pausch's dreams and impels us to contemplate our own. Mirroring the phases of Appreciative Advising, The Last Lecture facilitates our professional goal of enabling the dreams of the students we serve with a common approach, whether we work as orientation leaders, advisors, or instructors. Like the mirror in Snow White, The Last Lecture is an unusual mirror with the power to help students get a glimpse through the ivy-covered brick walls as they begin their journey inside.

\section{References}

Bloom, J. L., Hutson, B. L., \& He, Y. The appreciative advising revolution. Champaign, IL: Stipes Publishing LLC, 2008.

Cooperrider, D. L., Sorensen, P. F., Whitney, D., \& Yaeger, T. F. (Eds.). (2000). Appreciative inquiry: Rethinking human organization toward a positive theory of change. Champaign, IL: Stipes Publishing LLC.

Pausch, R., \& Zaslow, J. The last lecture. New York: Hyperion, 2008.

Zaslow, J. (2008). The last lecture. Retrieved from http://www.thelastlecture.com 